\title{
Spontaneous abortions and reproductive selection mechanisms in the rubber and leather industry in Finland
}

\author{
K HEMMINKI, ${ }^{1}$ MARJA-LIISA NIEMI, ${ }^{1}$ P KYYRÖNEN,$^{1}$ I KILPIKARI, ${ }^{2}$ AND H VAINIO ${ }^{1}$ \\ From the Department of Industrial Hygiene and Toxicology, ${ }^{1}$ Institute of Occupational Health, SF-00290 \\ Helsinki 29, and Nokia Ltd, ${ }^{2}$ Nokia, Finland
}

ABSTRACT Spontaneous abortions in hospitals were analysed from two sources-membership files of the Union of Rubber and Leather Workers (about 10000 women) and records of the personnel of a rubber factory (about 1600 women). Two frequencies of spontaneous abortions were calculated for each population analysed: rate (No spontaneous abortions $\times 100 /$ No pregnancies) and ratio (No spontaneous abortions $\times 100 /$ No births). The two frequencies were increased for all union members compared with all Finnish women. The frequencies, however, did not appreciably differ when the pregnancies occurred during union membership as compared with the pregnancies before or after membership. The frequency of spontaneous abortions was higher for the short-time union members than for those employed for longer periods, but the increased frequency did not correlate with union membership. The employees of a rubber factory had slightly fewer spontaneous abortions on average than the community population. The women employed in the rubber factory for three to 23 months were found to have appreciably higher frequencies of spontaneous abortions than the women employed for longer periods. The present study showed the feasibility of using cases of spontaneous abortions in hospitals in an occupational study with longitudinal employment data. Women with short periods of employment appeared to have more spontaneous abortions than those with longer periods of employment suggesting the presence of selection mechanisms, perhaps with some analogies to the "healthy worker effect" in occupational mortality studies. The presence of such selection mechanisms deserve serious consideration in occupational reproductive epidemiology.

A survey on the chemicals currently used in the rubber industry identified some 500 entities, many with limited toxicological data. ${ }^{1}$ In its present technology, rubber work entails a considerable amount of manual activity that prevents total isolation of the work processes. Many years ago rubber work was associated with an increased risk of cancer in the workers ${ }^{2}$; this has been confirmed in several later investigations. ${ }^{3-13}$ Female rubber workers have been reported as dying more frequently from lung cancer. ${ }^{5}$ Finnish rubber workers have excreted increased amounts of thioethers ${ }^{14}$ and mutagenic compounds ${ }^{15}$ in their urine.

In the present study spontaneous abortions of rubber and leather workers were investigated. The workers were identified from two independent sources-the membership files of the Union of

Received 15 June 1981

Accepted 22 March 1982
Rubber and Leather Workers and the records of the personnel of a rubber factory. All the spontaneous abortions in hospitals from 1973 to 1977 were identified from a computerised hospital discharge register. ${ }^{16-18}$ As many types of selection mechanisms operate in reproductive performance as well as in female employment, attempts were made to unravel such mechanisms. Additionally, the rubber industry served as a model of a heavy and demanding employment for women, and special methodological problems of such a study population were presented. This paper provides evidence on the feasibility of relating hospital records on spontaneous abortions to data on employment provided by trade unions and by companies.

\section{Material and methods}

The Finnish National Board of Health maintains a 
computerised hospital discharge register that includes all patients discharged from hospitals. We collected the registered information on patients treated for spontaneous abortions (ICD 643 and 645; women with diagnosis No 645 treated for induced abortion in the four preceeding months were removed), induced abortions (ICD 640-642), and deliveries (ICD 650662) from 1973 to 1977 . Some women with multiple (usually two) abortions were present in the series, but there was no evidence of bias because of this. The reproductive data were linked by personal identification code to the computerised membership registry of the Union of Rubber and Leather Workers. The union had about 10000 female members and the unionisation of labour in the rubber and leather industry was high, estimated at $95 \%$ by the union . officials. Almost all union members were full-time workers. According to the union officials the workers usually join during the month in which they start working. A worker who has not resigned but has failed to pay the fee for a half year will be dismissed. Our survey on this question with the rubber company data showed that half the workers joined and resigned within one month of the start or termination, respectively, of their work.

The register of the union contained information only on the current members in 1980. Data on the resigned members between 1975 and 1980 were collected from a special file. For all members we obtained information on the chapter to which the member belonged and when the member joined the union. For members who had resigned we collected also the date of resignation. The women were considered union-exposed members if they entered the union within three months of the conception, or if they resigned no later than the first month of their pregnancy. Only those women who belonged to the union two weeks or more during the two first months of their pregnancy were regarded as members. Those one-time union members who did not conform to these criteria formed a reference group. From the information of which chapters the members belonged to, and the main branches of employment of these local chapters, the members were classified into five occupational branches-rubber industry, shoe industry, leather industry, production of leather goods, and chapters with mixed industry.

For more specific information on rubber workers, the personnel of a rubber factory were investigated. This plant had about 1600 female workers of whom 450 worked in the tyre-manufacturing department and 1000 in the rubber shoe-manufacturing department. The data of the hospital discharge register from 1973 to 1976 were linked by personal identification code to the personnel register of the plant. Information on the exact occupation and the duration of employment in the factory was collected for all patients by the industrial health staff. Only those women who had worked in the factory during the first or second month of their pregnancy were included as exposed cases. The reference group was formed from those rubber workers who had worked at the factory but not at that stage of their pregnancy.

When calculating the frequencies of spontaneous abortions by the duration of employment in the factory, women employed for under three months were subtracted from the figures to eliminate vacation substitutes, as these might have biased the results.

The number of spontaneous abortions was related to the number of pregnancies (births + induced abortions + spontaneous abortions; this is referred to as the rate of spontaneous abortions) and to the number of births (referred to as the ratio of spontaneous abortions). Two different proportions for spontaneous abortions were calculated because of the large number of induced abortions in Finland. The rate is likely to underestimate the true frequency and the ratio is likely to overestimate it. Statistical significance was determined by the $X^{2}$ test for the rates and ratios. In the stratified data the significance was determined by the Mantel-Haenszel method and the homogeneity of strata was tested by a method based on the logarithms of the odds ratios.

Spontaneous abortions are also treated on an outpatient basis (policlinically) in Finland, and such patients are not registered by the National Board of Health. We have earlier estimated that they comprise $9 \%$ of all spontaneous abortions ${ }^{18}$ Our material included $93 \%$ of all deliveries, and $81 \%$ of induced abortions, estimated on the basis of official statistics. The loss of deliveries is due to defects in the cover of the register. The same also concerns induced abortions, but they too are induced policlinically in Finland. We assume that the omission of outpatient cases caused no severe bias in the present analysis.

The correctness of the diagnoses used has been evaluated in ad-hoc studies (M-L Niemi et al, unpublished data). Spontaneous abortions at one large hospital were listed and compared with the diagnoses given in the hospital records. An agreement was found in $91 \%$ of the cases.

\section{Results}

During 1973-7, the members of the Union of Rubber and Leather Workers had 128 spontaneous abortions in hospital, which resulted in the rate and ratio of spontaneous abortions of $7 \cdot 4$ and $10 \cdot 3$, both of which were only slightly higher than the corresponding frequencies for all Finnish women $(6 \cdot 6$ and $8 \cdot 9)$. The figures are based on workers in the age-groups 15-34 
years to reduce the effect of age on the comparison. Within various branches of the union, leather workers appeared to have more spontaneous abortions on average than the union members, although this difference was not significant (table 1). Workers in sections with mixed industries had less spontaneous abortions than all union members.

The effect of union membership on the outcome of the pregnancy was analysed by separating the spontaneous abortions taking place during union membership and before or after it (table 1). All the union members had about as many spontaneous abortions during membership as compared with the time before or after membership. Union membership appeared to increase the frequency of spontaneous abortions slightly (but not significantly) in leather and leather goods industries, while in the other branches no difference or a slight decrease was noted.

The frequency of spontaneous abortions was assayed at the time of the union membership for the women staying in the union and for those resigning from the union after pregnancy to test whether union membership was influenced by the outcome of the pregnancy. The frequency of spontaneous abortions was only slightly higher among the women who were to stay on in the union as compared with those resigning (rates 7.9 and 6.8 , respectively; the difference was not significant).
The women who had ever been members of the union were divided into four groups depending on the membership status during early pregnancy (member $v$ non-member) and on the duration of employment (over or under 24 months for the members, and over or under three months for the non-members). It was feasible to use different observation times for the members and non-members because the members with pregnancies had usually had relatively long periods of membership. Even though only a few spontaneous abortions could be analysed, the results appeared to indicate that the women who had been employed for short periods had had more spontaneous abortions than those who had been employed for longer (table 2). The difference was particularly clear for the women who were non-members during their pregnancy, and whose membership lasted for under three months. Interestingly, the group of women who had been employed for short periods also distinguished themselves by having more complicated pregnancies and induced abortions, granted on medical grounds, compared with other women (data not shown).

Further studies were carried out with the employees of a large Finnish rubber factory producing tyres and rubber shoes. The frequency of spontaneous abortions was compared with the figures for the whole community. The frequency of spontaneous

Table 1 Spontaneous abortions among rubber and leather workers (women aged 15-34) according to union membership during pregnancy 1973-7

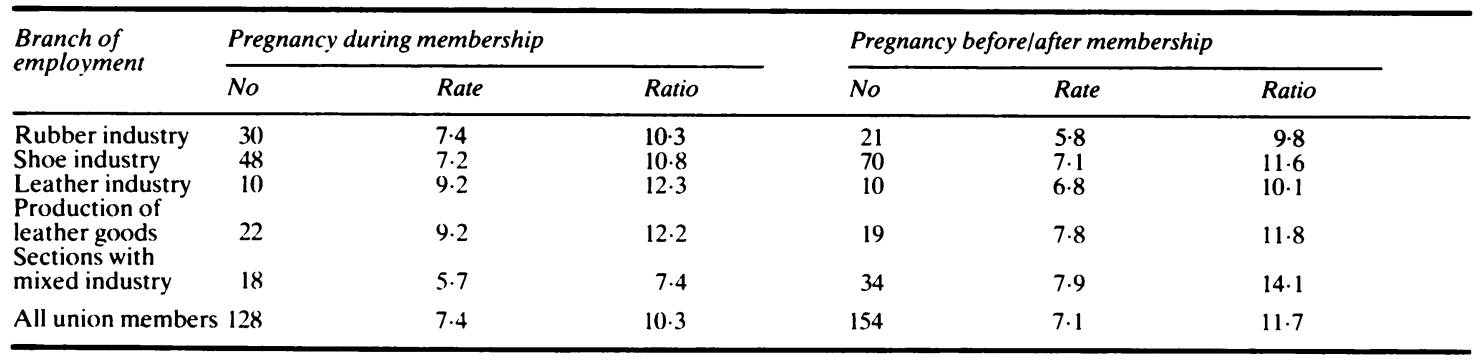

Table 2 Rate and ratio of spontaneous abortions among rubber and leather workers (women aged 15-34) who had resigned from the union by membership during pregnancy and by duration of union membership

\begin{tabular}{lccc}
\hline Duration of union membership & No of spontaneous abortions & Rate of spontaneous abortions & Ratio of spontaneous abortions \\
\hline Members & 10 & $8 \cdot 3$ & $14 \cdot 5$ \\
$<24$ months & 51 & $7 \cdot 7$ & $10 \cdot 5$ \\
$\geqslant 24$ months & 61 & $7 \cdot 8$ & $12 \cdot 6$ \\
Total & & & $12 \cdot 6^{*}$ \\
Non-members & 17 & $7 \cdot 3$ & $21 \cdot 5^{*}$ \\
$<3$ months & 51 & $8 \cdot 2$ & $11 \cdot 6$ \\
Total & 68 & $13 \cdot 1$ \\
\hline
\end{tabular}

${ }^{*} \mathrm{p}<0 .\left(05\right.$ as compared with the total frequencies, $X^{2}$-test. 
Table 3 Rate and ratio of spontaneous abortions among the workers of a rubber factory and the inhabitants of the community in 1973-6

\begin{tabular}{|c|c|c|c|c|c|c|}
\hline \multirow[t]{2}{*}{ Group } & \multicolumn{3}{|c|}{ All women } & \multicolumn{3}{|c|}{ Women aged 15-34 } \\
\hline & No & Rate & Ratio & No & Rate & Ratio \\
\hline \multicolumn{7}{|l|}{ Rubber workers } \\
\hline pregnancy & 25 & $7 \cdot 6$ & $10 \cdot 9$ & 20 & $6 \cdot 8$ & $9 \cdot 3$ \\
\hline Tyre department & 10 & $7 \cdot 8$ & $12 \cdot 0$ & 8 & $6 \cdot 6$ & 9.8 \\
\hline Shoe department & 15 & 7.4 & $10 \cdot 3$ & 12 & 6.9 & $9 \cdot 1$ \\
\hline $\begin{array}{l}\text { Rubber workers } \\
\text { non-employed }\end{array}$ & & & & & & \\
\hline during pregnancy & 20 & $7 \cdot 8$ & $13 \cdot 3$ & 19 & $7 \cdot 8$ & $12 \cdot 8$ \\
\hline the community & 135 & 9.7 & $15 \cdot 1$ & 116 & 9.2 & 13.4 \\
\hline
\end{tabular}

Table 4 Rate and ratio of spontaneous abortions among rubber workers (women aged 15-34) by employment during pregnancy and by length of time in the factory

\begin{tabular}{|c|c|c|c|c|c|c|c|c|c|}
\hline \multirow{3}{*}{$\begin{array}{l}\text { Employment } \\
\text { during } \\
\text { pregnancy }\end{array}$} & \multicolumn{9}{|c|}{ Length of time in the factory } \\
\hline & \multicolumn{3}{|c|}{$3-23$ months } & \multicolumn{3}{|c|}{$\geqslant 24$ months } & \multicolumn{3}{|c|}{ Total } \\
\hline & No & Rate & Ratio & No & Rate & Ratio & No & Rate & Ratio \\
\hline $\begin{array}{l}\text { Employed } \\
\text { Non-employed }\end{array}$ & $\begin{array}{r}5 \\
10\end{array}$ & $\begin{array}{l}12 \cdot 5 \\
10 \cdot 1\end{array}$ & $\begin{array}{l}29 \cdot 4^{* *} \\
17.2\end{array}$ & $\begin{array}{r}15 \\
6\end{array}$ & $\begin{array}{l}5 \cdot 9 \\
7 \cdot 6\end{array}$ & $\begin{array}{r}7.7 \\
12.5\end{array}$ & $\begin{array}{l}20 \\
16\end{array}$ & $\begin{array}{l}6.8 \\
9 \cdot 0\end{array}$ & $\begin{array}{r}9.4 \\
15 \cdot 1\end{array}$ \\
\hline Total & 15 & $10 \cdot 8^{*}$ & $20 \cdot 0^{* *}$ & 21 & $6 \cdot 3$ & $8 \cdot 6$ & 36 & 7.6 & $11 \cdot 3$ \\
\hline
\end{tabular}

${ }^{*} \mathrm{p}<\left(0.10 .{ }^{* *} \mathrm{p}<0.05 . X^{2}\right.$-test.

abortions was lower for the rubber workers than for the inhabitants of the community for all women as well as for women aged 15 to 34 years, although the difference was not significant (table 3 ). The women employed in the tyre department had an equally high rate of spontaneous abortions as the women employed in the shoe department. To unravel possible selection mechanisms operating, the factory workers were divided into four groups depending on the duration of employment and employment status during pregnancy. The short periods of employment (3-23 months) appeared to correlate with a high frequency of spontaneous abortions (table 4). Moreover, among the women who had worked for short periods, those working in the rubber factory during pregnancy had a higher frequency of spontaneous abortions than the ones who had not worked in the rubber factory.

\section{Discussion}

Occupational reproductive studies are infested with selection mechanisms, most of which have been poorly characterised. One of the most difficult selection mechanisms is the relation of reproductive events to a woman's employment. Even though we may be primarily interested in how working con- ditions influence pregnancy, we should not forget that pregnancy and its outcome influences a woman's employment by many mechanisms.

In occupational mortality studies the effect of selective processes, which often result in the better state of health of the working population compared with the general population, has been called "the healthy worker effect." $19-21$ This phenomenon has been divided into two components-selection into work and selection during the occupational history. 2122 The first selection mechanism has been called "the healthy population selection effect," the latter "the survivor population effect." Results emerging in our study seemed to relate to these two phenomena.

The first indication of healthy worker effect appeared when choosing the reference group. Among the workers at the rubber factory the frequency of spontaneous abortions was lower than among the other women of the community. This was probably due to a healthy population selection effect indicating that all other women of the community form an unsuitable reference group. Possibly those likely to abort spontaneously seek lighter and less hazardous occupations than rubber and leather work, or belong to the economically inactive population for reasons related to their poor health. Social factors 
probably also invalidate the comparison of factory workers with all other women of the community, as shown previously. ${ }^{17}$

To eliminate the effect of selection into rubber and leather work we formed the reference group from those workers whose pregnancy had been before or after the employment. The analysis suggested that the frequency of spontaneous abortion was independent of whether the pregnancy was conceived during the union membership or employment in the rubber factory. Interestingly, a subpopulation of women who had belonged to the union for under three months and who were non-members at the time of their pregnancy appeared to have an increased frequency of spontaneous abortions. This subgroup also distinguished itself from other workers by having more complicated pregnancies and induced abortions granted on medical grounds. This finding provided a further indication that some selection, based on reproductive health and related variables, may take place in the early days of employment. Women with a "non-occupational" liability for spontaneous abortions appear to terminate their employment quickly, in rubber and leather work at least. The investigation of the frequencies of spontaneous abortions among the rubber factory workers by duration of employment in the factory suggested further that some selection happens during occupational history. Short periods of employment associated with higher frequencies of spontaneous abortions than longer periods of employment. The existence of various subpopulations is a cause of concern when selecting a reference group. Ideally, another working population, with similar social characteristics, should be chosen, and periods of employment should be controlled.

Selection during the occupational history was investigated further by comparing the frequency of spontaneous abortions among those rubber workers remaining in or resigning from the union after their pregnancy. No large difference was noted between these two groups, suggesting that the reproductive events did not simply determine whether a woman stayed in the job or not. Among those who had resigned, however, were many who had obviously changed jobs or left the labour force for reasons unrelated to health. Child care is one of the most important reasons for a woman leaving work and these women may mask the possible existence of selection based on healthy factors.

Reasons for the present observations include one or more of the following: (1) recently employed people probably do the most hazardous work, (2) women with high non-occupational liability for spontaneous abortions may tend to be employed for short periods, and (3) women with conceived occupational hazards and spontaneous abortions may prefer to terminate their employment. Our data do not unambiguously distinguish between any of the above.

Reproductive epidemiology is still in its infancy and many selection mechanisms and risk factors have to be established before casual conclusions can be drawn in uncontrolled studies. In the present study we have unravelled some selection mechanisms hampering studies on spontaneous abortions in certain branches of industry. It is important to investigate whether similar selection mechanisms can also be identified among other groups of women. The selection, if present, may contribute to apparent false-negative results.

This work was supported by the Swedish Work Environmental Fund.

\section{References}

1 Holmberg B, Sjöström B. Toxicological aspects of chemical hazards in the rubber industry. J Toxicol Environ Health 1980;6: 1201-9.

2 Case RAM. Hosker ME. Tumor of the urinary bladder as an occupational disease in the rubber industry in England and Wales. Br J Prev Soc Med 1954:8:39-50.

${ }^{3}$ And jelkovich D. Taulbee I. Symons M. Mortality experience of a cohort of rubber workers. 1964-1973. JOM 1976:8:387-94.

${ }^{4}$ Andjelkovich D. Taulbee I. Symons M. Williams T. Mortality of rubber workers with reference to work experience. JOM 1977;19:397-405.

s Andjelkovich D. Taulbee I, Blum S. Mortality of female workers in a rubber manufacturing plant. JOM 1978:20:4(1)-13.

- Fox AJ, Collier PE. A survey of occupational cancer in the rubber and cablemaking industries: analysis of deaths occurring in 1972-4. Br J Ind Med 1976;33:249-64.

${ }^{7}$ Fox AJ, Lindars DC. Owen R. A survey of occupational cancer in the rubber and cablemaking industries: results of five year analysis, 1967-71. Br J Ind Med 1974;31:140-51.

* McMichael AJ. Spirtas R. Kupper LL. An epidemiologic study of mortality within a cohort of rubber workers. JOM 1974:16:45864.

9 McMichael AJ, Andjelkovich DA. Tyroler HA. Cancer mortality among rubber workers, an epidemiologic study. Ann NY Acad Sci 1976;271:125-37.

${ }^{10}$ McMichael AJ. Spirtas R. Gamble IF. Tousey PM. Mortality among rubber workers: relationship to specific jobs. JOM 1976: 18: $178-85$.

"Monson RR. Fine LJ. Cancer mortality and morbidity among rubber workers. J Natl Cancer Inst 1978;61:1047-53.

12 Monson RR. Nakano KK. Mortality among rubber workers. I. White male union employees in Akron. Ohio. Am J Epidemiol 1976;103:284-96.

13 Monson RR. Nakano KK. Mortality among rubber workers. II. Other employees. Am J Epidemiol 1976:103:297-303.

14 Vainio H. Savolainen H. Kilpikari I. Urinary thioethers of employees of a chemical plant. Br J Ind Med 1978:35:232-4.

15 Falck K. Sorsa M. Vainio H. Kilpikari I. Mutagenicity in urine of workers in rubber industry. Mutat Res 1980;79:45-52.

${ }^{16}$ Hemminki K. Franssila E. Vainio H. Spontaneous abortions among female chemical workers in Finland. Int Arch Occup Environ Health 1980;45:123-6.

17 Hemminki K. Niemi M-L. Saloniemi I. Vainio H. Hemminki E. 
Spontaneous abortions by occupation and social class in Finland. Int J Epidemiol 1980;9:149-53.

${ }^{18}$ Hemminki K. Niemi M-L, Koskinen K, Vainio H. Spontaneous abortions among women employed in metal industry in Finland. Int Arch Occup Environ Health 1980;47:53-60.

${ }^{19}$ Ogle W. Letter to the Registrar General on the Mortality in the Registration Districts of England and Wales during the ten years 1871-80. Forty-fifth annual report of the Registrar General of births, deaths and marriages in England-supplement 1871-80, Part 1, p xiii. London: Eyre \& Spottiswoode, 1885.

20 Goldsmith JR. What do we expect from an occupational cohort? JOM 1975:17:126-31.

21 Fox AJ. Collier PF. Low mortality rates in industrial cohort studies due to selection for work and survival in the industry. $\mathrm{BrJ} \mathrm{Prev}$ Soc Med 1976;30:225-30.

22 Vinni K. Hakama M. Healthy worker effect in the total Finnish population. BrJ Ind Med 1980; 37:180-4. 